We conclude that the factors likely to predispose an individual towards an adverse response are (a) genetic, (b) underlying immunopathological conditions, $(c)$ frequency of exposure to a particular drug, and $(d)$ various combinations of these. Genetic factors include both IgE (atopy) and complement anomalies. Immunopathological conditions involving circulatory immune complexes, such as chronic infection, systemic lupus erythematosus, and rheumatoid arthritis, may "prime" complement systems, making them susceptible to activation by intravenous drugs. Adverse response can thus be attributed to a range of mechanisms and predisposing factors and no intravenous drug can be considered entirely safe.

JOHN WATKINS

A MILFORD WARD Neil Appleyard

Departments of Immunology and Aallamshire Hospital

Sheffield

Watkins, J, et al, British fournal of Anaesthesia, 1976, 48, 457. et al, British fournal of Anaesthesia, 1976 , fournal of Anaesthesia, 1976, 48, 1118 .

\section{Adverse reactions to Althesin}

SIR,-Drs J M Evans and J A M Keogh report (17 September, $p$ 735) a high incidence of adverse reactions after the administration of Althesin (alphadolone and alphaxolone in polyoxyethylated castor oil; Bayer) and suggest that the number is unacceptable. I am concerned that the authors should consider that such a retrospective study would be expected to reveal an accurate picture of the number of adverse reactions that occurred. An anaesthetist is unlikely to recall all the untoward events that occur at induction over 3-4 years and would tend to remember events associated with a new drug rather than the routine agent. I cannot remember a single serious adverse reaction associated with my administration of intravenous anaesthetic agents, including Althesin, over the past six years but do not accept that this is evidence that none occurred. Close observation at the time of induction will show that all intravenous induction agents are associated with adverse effects and these are likely to be higher when a new drug is introduced, especially if it is potent. Drs Evans and Keogh attempt to classify the type of reaction that occurred. I doubt that this is possible from the information available in a retrospective study. It is important to differentiate between anaphylactoid reactions and the pharmacological effects of overdose. This requires measurement.

Over recent years I have administered many Althesin anaesthetics, and in many cases cerebral function has been monitored. There is no doubt that patients react very differently to a standard weight-based dose, some developing signs of profound cortical depression. Adequate anaesthesia may be induced with only $1.5-2.5 \mathrm{ml}$ of Althesin yet anaesthetists, used to injecting $12-15 \mathrm{ml}$ of thiopentone, might not have adapted to the smaller volumes required when using Althesin.

Thiopentone was once described as an ideal method of euthanasia in war surgery. ${ }^{1}$ Its popularity could well have declined but for a further publication which suggested that it was the technique of administration and the dose of drug used that was at fault rather than the agent itself. ${ }^{2} 3$ We may now be seeing a similar situation with Althesin. Serious complications are likely to be reduced if induction agents are administered slowly in small doses, if blood pressure, heart rate, and even cerebral function are monitored during the induction period, and if an intravenous infusion is readily available. The incidence of anaphylactoid reactions will have to be worked out from the results of haematological and biochemical measurements. These may ultimately show that Althesin is particularly prone to induce adverse effects but I do not think one can accept the findings of a retrospective study. Meanwhile one can ponder on the mechanism of apnoea lasting 60 minutes after a single dose of Althesin. Someone could not possibly have given the wrong drug, could they?

T M SAVEGE Acting Director,
Anaesthetics Unit London Hospital Medical College,
London El

Halford, F J, Anesthesiology, 1943, 4, 67

Adams, R C, and Gray, H K, Anesthesiology, 1943, 4, Editorial, Anesthesiology, 1943, 4, 66

Seniority payments and service in HM Forces

SIR,-Dr W A Jerrett in his letter (17 September, $p$ 774) draws attention to a gross injustice in that service in the armed Forces does not count towards seniority in general practice, except as a "senior" medical officer. The Ministry of Defence should now warn all serving and potential medical officers that their five years of service, even if spent in general practice, will not count towards seniority payments. Perhaps they could include this information in the recruiting information they send to medical students who apply to join the armed Forces.

Pont ypridd,
Mid Glamorgan

C B A LlOYD-WILliaMS

\section{General practitioner prescribing costs}

SIR,-Dr R T A Scott's letters (30 July, p 319, 10 September, $p$ 708) raised two very different questions. His suggestion in the later letter of a limited list of drugs for free or subsidised use is an attractive one and makes the prescribers' decisions much easier. Dr Scott's first question about the teaching of future general practitioners is even more pertinent now that, according to the DHSS's annual report of 1976, English general practitioners' prescribing costs averaged more than $£ 22000$ each. Classes on prescribing costs were begun in the Wessex day-release course in 1974, when a colleague presented the results of a prescription pricing inquiry into his practice. This was followed by exercises in practical prescribing and questions on attitudes to prescribing. These clearly confirmed that "the question of cost plays no part in choosing drug treatments" was a view prevalent among trainees in 1974-5. Since then further classes have been held and the discussion of cost is now seen by trainees as a factor of importance in choosing treatment, especially where doctors try to agree on joint policies. Even so, we recognise that economy in GP prescribing costs can play only a limited part in keeping down the cost of the health service. A $12 \%$ reduction in prescribing (requiring an average of 150 fewer prescriptions per doctor per month) would result in less than $1 \%$ change in the total cost of the NHS.

P P CARTER

Southampton,

Hants

\section{Costs of prescribing}

SIR,-_Professor O L Wade recently delivered a lecture to the British Association for the Advancement of Science on "The problems (of the cost) of Drug Prescribing in the National Health Service." In it he evaluates most helpfully many of the problems in financing medication. ${ }^{1}$ However, towards the end of the paper he suggests that monetary incentives could be used to curb wasteful prescribing in general practice. "Each doctor might be given a 'drug allowance' of $£ 400$ to $£ 500$ per 100 patients on his list to meet the cost of his prescribing. If he prescribes in excess of this, other than in exceptional circumstances, the excess would be met from his practice; if he prescribes within his budget the saving would accrue to his practice to be available for other services."

Unfortunately, one of the snags of the pool as a method of payment is that no one group of doctors can be given additional sums of money without this being subtracted at national level from the remuneration of all remaining practitioners. Thus, what sets out to be an inducement turns out to be a penalty, particularly on the conscientious doctor as well as to the body of general practitioners as a whole. I remember the days when I used to dispense for my own rural practice and chose the capitation system (now 52p per patient). I am well aware of the substantial savings available to be made from prescribing what one dispenses-but in urban practice, with independent chemists, the problem is more complex. The outcome of this system of pseudo inducements would lead to deterioration of health care.

At present there are only a few drugs, borderline substances, for which the GP may be asked to undertake the cost of prescribing himself. Legislation of this type would convert all drugs to this class in that the practitioner would be at risk to cover the cost of his patients' needs should they rise above an arbitrary limit. With inflation raising the price of drugs, increased reluctance of hospitals to prescribe what they recommend, and inflation massively eroding the doctors' income, that proportion of the cost of the doctors' drug bill which politicians would allow to fall as a debt on our pockets would be bound to increase to save the public purse.

Doctors with a large turnover of mobile patients, those looking after a preponderance of the elderly, those caring for homes for the elderly, subnormal, or mentally handicapped -all these doctors would find themselves penalised in so far as their drug expenses would be disproportionately high for having accepted responsibility for more difficult patients. What doctor would involve himself in screening his practice if the cost of treating identified cases might fall on his own pocket? What chance have ill patients of being accepted by a new doctor if he can see that they are persons liable to require expensive medication? What GP can afford to look after a child who, happening to have phenylketonuria, has come 
to expect a monthly prescription in excess of $£ 100$ ? In many of these situations the general practitioner would find himself in the position of having to choose between the care of his patients and being able to retain his legitimate income for his own and his family's use.

Too heavy a burden of sanctions must only act to increase the internal conflict that a practitioner accepts in undertaking to look after an NHS list of patients. This must lead to an attrition of good service and to bad feelings. This, I would predict, would be soon discernible from the retirement, emigration, and suicide rates of general practitioners. The very complexity of the pool system makes it difficult to reward the careful rather than the lazy doctor. Simplistic attempts to use financia incentives within that system can easily have very different effect from what was intended.

\section{A R DEwsBury}

\section{Birmingham}

Clinical Practice in its Economic Context, ed C I
Philips and J N Wolfe. London, Pitman, 1977.

\section{A tennis elbow support}

SIR,-I was interested to read the letter by Mr S C Chen (1 October, p 894) on the tennis elbow support. His preliminary results are impressive, but I would like to point out that an almost identical support has been described elsewhere, ${ }^{1}$ with similar encouraging results.

ANTHONY J RICHARDS

Department of Rheumatology,

Worthing Hospital,

Sussex

'Froimson, A I, fournal of Bone and foint Surgery,
1971, 53-A, 183.

\section{Bell's palsy and herpes simplex}

SIR,-Dr P Grout (24 September, p 829) describes a patient who had facial nerve palsy and stomatitis. It is postulated that the motor nerve palsy was due to herpes simplex virus. The evidence for this is quite inadequate. There is no substantive evidence that the stomatitis was due to herpes simplex, and only positive cultures could have proved that. W are told that there were "very high antibody titres to HSV and varicella-zoster (V-Z)" but we are not told what the titres were.

Dr F O MacCallum and I investigated many patients with Bell's palsy, but we never found any evidence that it was due to herpes simplex virus. This does not mean to say that it could not happen. Facial palsy certainly can be part of the picture of herpes simplex virus encephalitis. Stomatitis in encephalitis must be extremely rare, as it is practically never possible to recover the virus from sites outside the central nervous system. On the other hand facial palsy is perhaps the commonest form of $\mathrm{V}-\mathrm{Z}$ motor nerve involvement, alone or in association with sensory zoster. We are told that there were paraesthesiae in the area of the Vth nerve. As mentioned above, we were not told what the titre of antibody to $\mathrm{V}-\mathrm{Z}$ was, but I would submit that it is far more likely that Dr Grout's patient's motor palsy of the facial nerve was due to $\mathrm{V}-\mathrm{Z}$ virus than to herpes simplex virus. This does not preclude the possibility that the patient also had herpes simplex stomatitis, but without paired sera or positive cultures we shall never know. We were not told if the lesions were unilateral; if they were it is possible that the lesions in the mouth could have been due to zoster of the maxillary and mandibular divisions of the trigeminal nerve.

BENT JUEL-JENSEN

Radcliffe Infirmary,

Oxford

\section{Questionnaires and abuse of privacy}

SIR,-A short time ago I received a letter and questionnaire from the Medical Care Research Unit, Department of Community Medicine, University of Sheffield Medical School. The letter explained that research was being done into the problems that women face in pursuing their careers. On turning to the questionnaire I read the questions with growing disbelief. Not only was I expected to identify myself and every detail of my career completely, I was also expected to identify my parents and their occupations, and details of my husband's career if he happened to be a medical doctor.

How dare anyone under the excuse of research make such an invasion of one's privacy! Surely the answers to the problems (if any) of women in medicine can be obtained by other questions or methods. I have protested by letter to the person who sent out the questionnaire. I hope that all the other women doctors who have received such requests have either ignored them or, better still, protested as I have done. There are too frequently such blatant abuses of privacy at the present time.

Fleetwood, Lancs

Aline Sullivan

\section{Vitamin $B_{12}$ deficiency in a child}

SIR,-I was interested to read of the case of vitamin $\mathrm{B}_{1,2}$ deficiency in a child described by Dr D Attock and his colleagues (24 September, p 807). I find it surprising that a jejuna biopsy was not performed since $\mathrm{B}_{12}$ deficiency occurs commonly in coeliac disease. ${ }^{1}$ Lack of steatorrhoea," normal small-bowel radiology, and normal serum levels of folate, calcium phosphate, magnesium, and vitamin A do not exclude the diagnosis of coeliac disease. ${ }^{4}$

Using a paediatric small-intestinal biopsy capsule jejunal biopsy is a safe procedure and is not distressing to children when performed with a suitable introducer and using intravenous diazepam and metoclopramide. Indeed, by screening the position of the capsule with an image intensifier jejunal biopsy can often be performed within 5-10 minutes. It seems a pity not at least to exclude the diagnosis of coeliac disease in patients with malabsorption of $B_{1 .}$ since the condition can be readily treated with a gluten-free diet and the longterm complications of the undiagnosed disease avoided.

General Hospital,

R FERGUSON

General Hospita
Nottingham

'Hoffbrand, A V, in Clinics in Gastroenterology: Coeliac Disease, ed W T Coc

McNeish, A S, and Anderson, C M, in Clinics in Gastroenterology: Coeliac Disease, ed W T Cook and P Asquith, p 131. London, Saunders, 1974. ${ }^{3}$ Burrows, F G O, and Toye, D K M, in Clinics in Gastroenterology: Coeliac Disease, ed W T Cooke and $P$ Asquith, $p 104$. London, Saunders, 1974.

Ferguson, R, MD Thesis, University of Birmingham
Mobilisation after myocardial infarction

SIR,-Your leading article on this subject (10 September, p 651) states that the benefit of "a formal programme of physical training in a physiotherapy department or gymnasium" should be set against "the expense and time, the high drop-out rate, and the uncertainty that the long-term prognosis is improved."

This hospital has been offering a physical training programme to selected patients after myocardial infarction over the past seven years and the only expense incurred is the salary of a part-time physiotherapist, the medical staff being on call to the coronary care unit. ${ }^{1}$ The patients and their wives have been enthusiastic about the service and feel that it has improved their morale, physical fitness, and capacity both to work and to follow leisure pursuits.

We feel that there is no reason why a district hospital with coronary care responsibility should not offer this valuable and economic service.

D MCC BOYLE

J M BARBER

PATRICIA MCCOY

Ulster Hospital,

Belfast

Singh, N S, et al, fournal of the Irish Medical Associa-

Immunological deficiency, cancer, and prostaglandins

SIR,-Your leading article (10 September, p 654) expressed the hope that fundamental research may one day enable some form of biological engineering to correct the fault in congenital immunodeficiency disease. We suggest that in one form of immunodeficiency disease such "engineering" has been successfully used since 1953. The failure of research workers to recognise this is an interesting example of the danger of specialisation.

Acrodermatitis enteropathica (AE) is a congenital disease which presents soon after birth with severe acral dermatitis, total alopecia, and gastrointestinal disturbances. The skin disorder usually ensures that affected infants are referred to a dermatologist, who recognises $\mathrm{AE}$ and prescribes dihydroxyiodoquin, penicillamine, or zinc. Dihydroxyiodoquin was empirically found successful in $1953,{ }^{1}$ while the use of penicillamine was reported in 1963. More recently AE was found to be associated with zinc deficiency and zinc seems to produce a complete symptomatic cure. ${ }^{3+}$ Patients with $\mathrm{AE}$ have therefore no reason to be seen by specialists in immunodeficiency disease.

It is only on reading papers written by those who attempted to treat the disease before 1953 or who have had experience of a patient with AE which was not diagnosed as such until a late stage that the connection between $\mathrm{AE}$ and immunodeficiency can be appreciated. Untreated $\mathrm{AE}$ is associated with total or neartotal absence of the thymus, hypotrophic or absent tonsils, Peyer's patches, and peripheral lymph nodes, and evidence of both $\mathrm{T}$ and $\mathrm{B}$ lymphocyte deficiency." "There are multiple infections difficult or impossible to treat with antibiotics. Candida and pseudomonas are common infecting organisms and in several cases which came to necropsy the described lung changes were consistent with Pneumocystis carinii infection. 711

It seems to us therefore that $\mathrm{AE}$ is a form of immunodeficiency disease which, with its 